\title{
RELAÇÃO ENTRE TEORES DE COLESTEROL EM FILÉS DE TILÁPIAS \\ E NÍVEIS DE ÓlEO DE LINHAÇA NA RAÇÃO'
}

\author{
Jesuí Vergílio VISENTAINER ; Tatiana SALDANHA ; \\ Neura BRAGAGNOLO ; Maria Regina Bueno FRANCO
}

\section{RESUMO}

O objetivo deste trabalho foi investigar o efeito de rações contendo diferentes niveis de óleo de linhaça no teor de colesterol e na composição centesimal (umidade, cinza, proteína e lipídios totais) de filés de tilápia. A determinação do colesterol foi realizada através de cromatográfica líquida de alta eficiência (CLAE). Esta metodologia foi avaliada no presente trabalho mostrando-se exata e precisa. Os teores de colesterol variaram de 58,3 a $75,5 \mathrm{mg} / 100 \mathrm{~g}$ de tecido muscular, sendo que a inclusão de óleo de linhaça em um nível de até $3,75 \%$ favoreceu a diminuição dos valores de colesterol nos filés de tilápia. No entanto, os niveis de colesterol foram próximos a outras espécies de peixes. Na composição centesimal não houve diferença significativa entre os diferentes tratamentos. Desta forma, a utilização de óleo de linhaça não apresentou influência na composição dos constituintes analisados.

Palavras-chave: colesterol; composição centesimal; tilápias; linhaça.

\section{SUMMARY}

RELATIONSHIP BETWEEN CONTENT OF CHOLESTEROL IN FILETS OF TILAPIAS AND LEVELS OF LINSEED OIL RATION. ThE objective of this study was to investigate the effect of fish feed containing different levels of linseed oil on the cholesterol content and proximate composition (moisture, ash, protein and total lipids) of tilapia fillets. The cholesterol content was determined using high performance liquid chromatography (HPLC), the methodology being evaluated and validated and shown to be exact and precise. The cholesterol contents varied from 58 to $76 \mathrm{mg} / 100 \mathrm{~g}$ of muscle tissue, the inclusion of linseed oil up to a level of $3.75 \%$ favoring a decrease in the cholesterol content of the tilapia fillets, although the levels continued to be similar to those of other fish. There was no significant difference between the treatments with respect to the proximate composition. Thus the use of linseed oil presented no influence on the composition of the constituents analyzed.

Keywords: cholesterol; proximate composition; tilapias; linseed.

\section{1 - INTRODUÇÃO}

Nos últimos anos, no Brasil, houve um aumento na criação de novas espécies de peixes de cativeiro e, conseqüentemente, no consumo. Isto ocorreu devido às condições hidrográficas favoráveis, ao crescente número de "pesque-pague", "pague-pesque" e ao fornecimento de peixes pelos criadores que vendem seus produtos em mercados, feiras-livres e indústrias de filetagem. Destacamse principalmente espécies como a tilápia (Oreochromis niloticus) que apresenta uma boa aceitação pelo consumidor, com preços mais acessíveis em relação a outros peixes.

São vários os fatores que determinam a composição química de uma espécie de peixe. Dentre estes, podemos citar a alimentação, genética, sexo, tipo e época da desova, estágio produtivo, tamanho e migração, além de fatores ambientais relacionados com variações em seu habitat e formas de criação. A influência da temperatura, vari-

Recebido para publicação em 06/02/2004. Aceito para publicação em 15/04/2005 (001287).

Departamento de Quimica, Universidade Estadual de Maringá. End.:, Av. Colombo 5790, CEP: 87020-900 - Maringá, PR. E-mail: juvisentainer@uem.br

Departamento de Ciência de Alimentos, Faculdade de Engenharia de Alimentos, Universidade Estadual de Campinas, C. P.: 6121. CEP: 13083-862, Campinas, SPl.

A quem a correspondência deve ser enviada. ação no volume de água e a estação do ano afetam diretamente a disponibilidade de alimento para os peixes e têm sido objetos de vários estudos nos últimos anos [2, 10, $18,26]$. A dieta dos peixes influencia a composição do tecido muscular e, especialmente, a composição de ácidos graxos dos lipídios deste tecido.

Pesquisas vêm estabelecendo, continuamente, que um aumento na ingestão de ácidos graxos poliinsaturados ômega-3 (AGPI n-3) reduz a taxa de triacilgliceróis no sangue [7]. Além disso, estudos realizados com base em intervenções de dietas comprovaram que o consumo de AGPI e/ou óleos de pescado reduz fatores bioquímicos de risco associados a doenças cardiovasculares [15], artrite e câncer [13, 22] e pode estar envolvido com a fertilidade humana [4].

Uma das alternativas para aumentar a ingestão de AGPI n-3 é a inclusão de peixes de cativeiro de água doce na alimentação. Entretanto, estudos demonstraram que peixes de cativeiro, alimentados exclusivamente com rações comerciais, apresentaram baixos teores de AGPI n-3 quando comparados com espécies nativas [17, 18, 25].

A inclusão de rações suplementadas com óleo de linhaça demonstraram um aumento significativo nos teores de AGPI n-3 nos filés de tilápia (Oreochromis niloticus) que foram submetidas a tratamentos com niveis crescentes deste óleo de linhaça nas rações [24]. Isto ocorreu devido ao ácido alfa-linolênico (LNA, 18:3n-3) estar pre- 
sente em elevados teores na semente de linho (Linum usitatissimum) e ser um precursor metabólico de outros AGPI n-3 de importante valor nutricional como os ácidos eicosapentaenóico (EPA, 20:5n-3) e docosahexaenóico (DHA, 22:6n-3).

Do ponto de vista nutricional, em humanos, o colesterol no plasma não depende somente do componente colesterol, mas também da composição de ácidos graxos da dieta. O efeito dos ácidos graxos oriundos da dieta sobre os niveis de colesterol plasmático tem sido descrito por mais de 30 anos [11]. Estudos mostraram que a ingestão de ácidos graxos saturados aumenta os niveis de colesterol sérico em humanos $[8,12]$, enquanto os níveis de colesterol total no plasma sangüíneo diminuem, quando a ingestão de ácidos graxos saturados é substituída por monoinsaturados [7].

Os objetivos deste trabalho foram avaliar a influência de rações com diferentes níveis de óleo de linhaça sobre os teores de colesterol e na composição centesimal (umidade, proteína, cinza e lipídios totais) no tecido muscular de tilápias (Oreochromis niloticus), e validar metodologia para determinação de colesterol em amostras de peixe por cromatografia líquida de alta eficiência (CLAE).

\section{2 - MATERIAL E MÉTODOS}

\section{1 - Sistema de confinamento, preparo das amostras e rações}

$\mathrm{Na}$ estação de Aquicultura do Departamento de Biologia da Universidade Estadual de Maringá, PR, exemplares juvenis (média aproximada de $88 \mathrm{~g}$ em massa e $15 \mathrm{~cm}$ de comprimento) de tilápia (Oreochromis niloticus) foram submetidos a um sistema de confinamento. Em 25 tanques de fibro-cimento (capacidade de 1000L/cada), foram colocados 5 exemplares/caixa e alimentados por 5 meses.

O experimento foi inteiramente casualizado com 5 tratamentos (diferentes níveis de óleo de linhaça) e 5 repetições.

Após os 5 meses do experimento, os filés (tecido muscular) dos exemplares de tilápias de cada repetição foram removidos e imediatamente acondicionados em embalagens de polietileno sob atmosfera de $\mathrm{N}_{2}$ gasoso e congelados a $-18^{\circ} \mathrm{C}$ até o início das análises. Em seguida, estes foram descongelados a temperatura ambiente e, em seguida, triturados em processador de alimentos (FAET, Multipratic). Alíquotas convenientes do tecido muscular de cada repetição foram tomadas para as análises de umidade, cinza, proteína, lipídios totais e colesterol.

Os níveis suplementares do óleo de linhaça em massa, nas rações, foram crescentes recebendo os niveis percentuais de 0,$00 ; 1,25 ; 2,50 ; 3,75$ e $5,00 \%$ para os tratamentos A, B, C, D e E, respectivamente, conforme Tabela 1 , enquanto que os níveis do óleo de girassol foram complementares para atingir o nível máximo de $5,00 \%$ de óleo adicionado.
O óleo de linhaça (fonte de LNA), utilizado no experimento foi fornecido pela empresa GIOVELLI \& CIA. LTDA., instalada na cidade de Guarani das Missões, RS. O óleo na forma bruta foi extraído através de prensa mecânica (tipo expeler) e filtrado em filtro prensa com a utilização de pano de algodão. Este óleo apresentou 45,7\% de LNA em percentagem de área relativa.

O óleo de girassol refinado da marca VIGOR, pertencente ao mesmo lote, foi obtido no comércio de Campinas, SP e utilizado no controle (tratamento A) e complementação dos níveis lipídicos do óleo de linhaça das rações dos tratamentos B, C e D. O óleo de girassol foi utilizado neste experimento por ser acessivel e apresentar baixos teores do ácido LNA $(0,4 \%$ em percentagem de área relativa).

A Tabela 1 mostra a composição percentual em massa das diferentes rações com os diferentes níveis de óleo de linhaça e girassol, que foram fornecidas para as tilápias, conforme patente requerida n. PI 0202892-1 (UNICAMP - INPI, 2002).

TABELA 1 - Composição percentual das rações dos diferentes tratamentos

\begin{tabular}{|c|c|c|c|c|c|}
\hline \multirow[b]{2}{*}{$\begin{array}{c}\text { CONSTITUINTES } \\
(\%)\end{array}$} & \multicolumn{5}{|c|}{ TRATAMENTOS } \\
\hline & A & $\mathrm{B}$ & $\mathrm{C}$ & $\mathrm{D}$ & $\mathrm{E}$ \\
\hline Milho moído & 16,93 & 16,93 & 16,93 & 16,93 & 16,93 \\
\hline Farelo de Soja Desengordurado & 51,62 & 51,62 & 51,62 & 51,62 & 51,62 \\
\hline Farelo de Trigo Comercial & 20,00 & 20,00 & 20,00 & 20,00 & 20,00 \\
\hline Bagaço de Cana & 1,28 & 1,28 & 1,28 & 1,28 & 1,28 \\
\hline Calcário & 1,74 & 1,74 & 1,74 & 1,74 & 1,74 \\
\hline Fosfato Bicálcico & 2,41 & 2,41 & 2,41 & 2,41 & 2,41 \\
\hline Óleo de Linhaça & 0,00 & 1,25 & 2,50 & 3,75 & 5,00 \\
\hline Óleo de Girassol & 5,00 & 3,75 & 2,50 & 1,25 & 0,00 \\
\hline $\mathrm{BHT}^{1}$ & 0,02 & 0,02 & 0,02 & 0,02 & 0,02 \\
\hline $\mathrm{NaCl}$ & 0,50 & 0,50 & 0,50 & 0,50 & 0,50 \\
\hline Suplemento Mineral e Vitamínico ${ }^{2}$ & 0,50 & 0,50 & 0,50 & 0,50 & 0,50 \\
\hline Lipídios totais $^{3}$ & $7,6 \pm 0,3$ & $7,7 \pm 0,4$ & $8,0 \pm 0,6$ & $8,0 \pm 0,7$ & $7,8 \pm 0,3$ \\
\hline Umidade $^{3}$ & $9,7 \pm 1,4$ & $9,6 \pm 1,4$ & $9,6 \pm 1,6$ & $9,4 \pm 1,7$ & $9,9 \pm 2,0$ \\
\hline \multicolumn{6}{|c|}{ 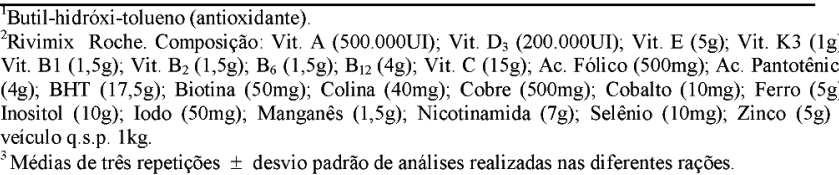 } \\
\hline
\end{tabular}

\section{2 - Métodos}

As análises de umidade, cinza e proteína bruta foram realizadas conforme técnicas da AOAC [6]. Na extração e quantificação dos lipídios totais, foi empregado o método de BLIGH \& DYER [3].

\subsection{1- Determinação de colesterol por CLAE}

A Figura 1 representa o fluxograma analítico para determinação de colesterol nas amostras de peixe. A obtenção da matéria insaponificável foi realizada através de saponificação direta das amostras, de acordo com NOGUEIRA \& BRAGAGNOLO [19].

Utilizou-se um cromatógrafo líquido (SHIMADZU) equipado com sistema ternário de solventes $\left(\mathrm{LC} 10 \mathrm{AD}_{v}\right)$, 
válvula "Rheodyne" com alça de amostragem de $20 \mu \mathrm{L}$, forno com controle de temperatura mantido a $32^{\circ} \mathrm{C}$, desgaseificador "on line", detector UV-Visivel (SPD-10 AV v $_{\text {p }}$ ) e software (CLASS-VP10) para aquisição e processamento de dados. A coluna analítica usada foi $\mathrm{C}_{1 \mathrm{~s}}, 150$ x 4,6mm x $4 \mu \mathrm{m}$ (VARIAN). A fase móvel constituiu-se de acetronitrila:isopropanol (70:30), na vazão de $1 \mathrm{~mL} / \mathrm{min}$, sendo o tempo de análise 18 minutos. Os solventes utilizados foram grau cromatográfico, filtrados em sistema MILLIPORE de filtração a vácuo, com membrana para solvente orgânico de $0,25 \mu \mathrm{m}$ e desgaseificados em ultrasom antes do uso. Os cromatogramas foram processados

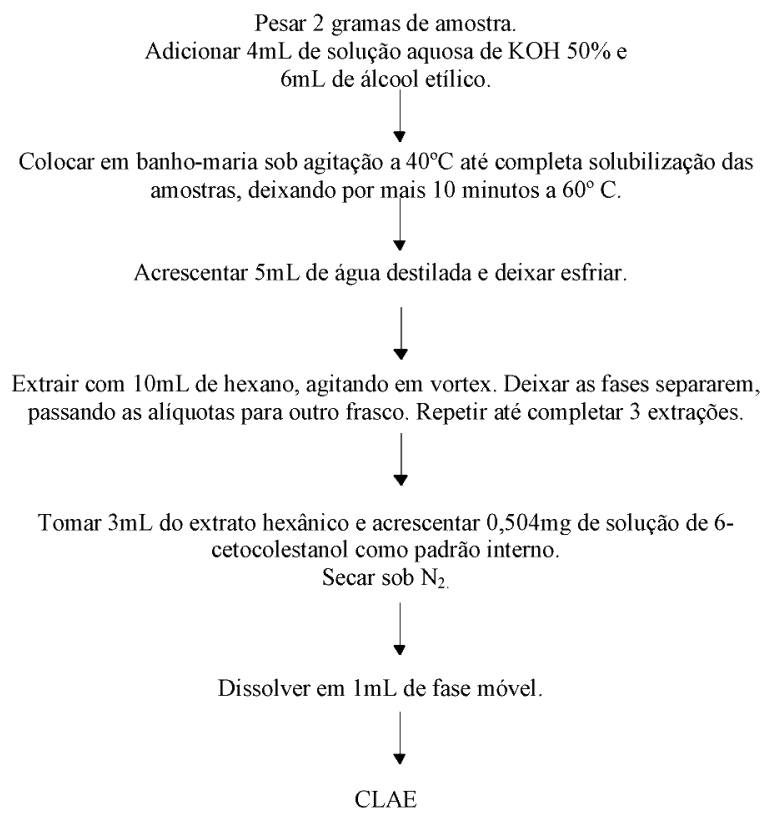

Condições cromatográficas: coluna $\mathrm{C}_{18}$, Fase móvel acetonitrila: isopropanol (70:30 vazão $1,0 \mathrm{~mL} / \mathrm{min}$; detector UV-Visivel a $210 \mathrm{~nm}$

FIGURA 1 - Fluxograma para determinação do colesterol em peixes por CLAE a $210 \mathrm{~nm}$. A identificação do colesterol foi realizada através de comparação do tempo de retenção das amostras com o padrão e por co-cromatografia. A quantificação foi feita por padronização interna usando 6-cetocolesterol (SIGMA \& POLYSCIENCE, K 1250, USA) como padrão interno. O fator resposta foi calculado diariamente. A Figura 2 apresenta um cromatograma característico de colesterol na amostra de peixe.

\section{Validação da metodologia}

A metodologia utilizada para a determinação de colesterol em peixes foi validada no presente trabalho através da recuperação e da repetibilidade. A recuperação foi realizada adicionando-se dois niveis de colesterol às amostras de filé de tilápia $(0,503$ e $1,006 \mathrm{mg})$ sendo realizadas 5 repetições para cada nível de adição. A precisão foi observada através dos coeficientes de variação de 10 repetições de uma mesma amostra. Embora a matriz não seja a mesma foi utilizado também para a validação material de referência certificado de carne (SRM 1546, NIST).

Os resultados dos testes de recuperação foram de $94,0 \pm 1,0$ e $97,0 \pm 1,0 \%$ para os dois niveis adicionados, 0,503 e $1,006 \mathrm{mg}$, respectivamente. O coeficiente de variação $(\% \mathrm{CV})$ encontrado para 10 repetições de amostras de peixe foi de $1 \%$ demonstrando boa precisão da metodologia. Os teores de colesterol determinados para o material de referência certificado de carne (SRM 1546, NIST) foram de 75,0 $\pm 0,5 \mathrm{mg} / 100 \mathrm{~g}$, sendo semelhante ao declarado no certificado $(75,0 \pm 7,0 \mathrm{mg} / 100 \mathrm{~g})$, demonstrando que a metodologia utilizada foi exata e precisa.

Os resultados obtidos foram submetidos à análise de variância (ANOVA) a 5\% de probabilidade, pelo teste de Tukey, através do software Statistica, versão 5.0 [23].

\section{3 - RESULTADOS E DISCUSSÃO}

Os valores médios de umidade, cinza, proteína e lipídios totais não apresentaram diferenças significativas $(\mathrm{P}>0,05)$, entre os tratamentos que continham o óleo de linhaça (Tabela 2).

Os teores de umidade encontrados neste experimento variaram de 76,8 a $77,4 \%$ e são próximos aos encon-

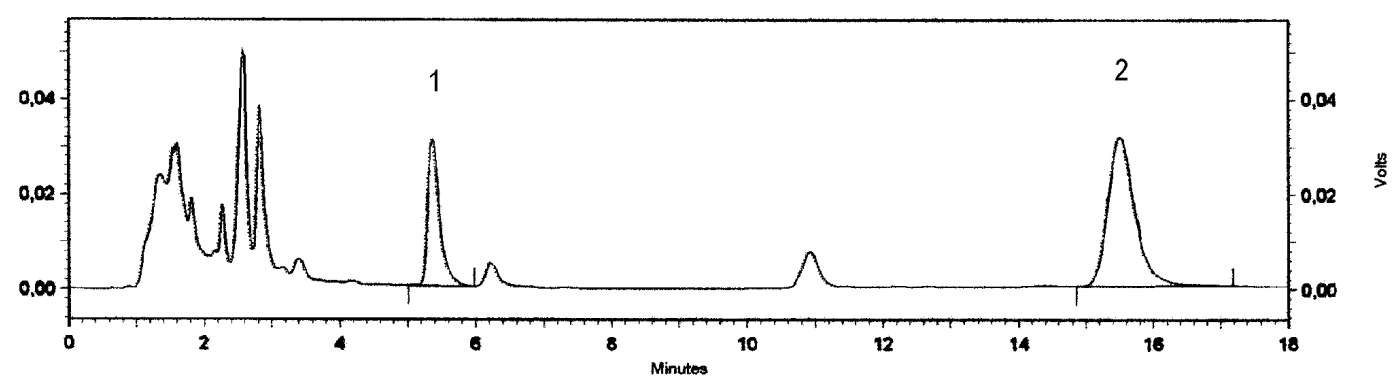

FIGURA 2 - Cromatograma característico de colesterol em peixe obtido por CLAE. Condições cromatográficas: Fase móvel, acetonitri-

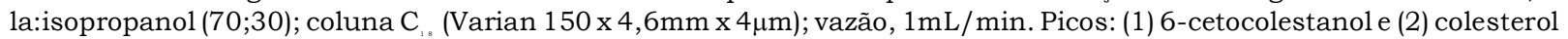


[3] BLIGH, E. G., DYER, W. J. A rapid method of total lipid extraction and purification. Canadian Journal of Biochemistry, v. 37, n.8, p. 911-917, 1959.

[4] CONQUER, J. A.; MARTIN, J. B.; TUMMON, I.; WATSON, L.; TEKPETEY, F. Effect of DHA supplementation on DHA status and sperm motility in asthenozoospermic males. Lipids, v. 35, p. 149-54, 2000.

[5] CRINER, P., FEELEY, R. M. Evaluating analytical data on cholesterol in foods. Journal of the American Dietetic Association, v. 61, p. 115-125, 1972.

[6] CUNNIF, P. A. 1998. Official Methods of Analysis of AOAC International. 6th ed. Arlington: Association of Official Analytical Chemists.

[7] DEPARTMENT OF HEALTH. Report on Health and Social Subjects $n^{\circ} 46$. Nutritional Aspects of Cardiovascular Disease. HMSO, London, 1994, 178p.

[8] EWIN, J. 1997. O Lado Sadio das Gorduras. Trad. de Ana Beatriz Rodrigues. Editora Campus Ltda, Rio de Janeiro, 162p.

[9] FERREIRA, F. G.; VISENTAINER, J. V.; CATHARINO, R. R.; FRANCO, M. R. B. Composição química e de ácidos graxos em filés de tilápias (Oreochromis niloticus) submetidas a dois sistemas de criação. IV Brazilian Meeting On Chemistry of Food and Beverages, Campinas, Unicamp, dezembro 2002.

[10] HENDERSON, R. J.; TOCHER, D. R. The lipid composition and biochemistry of freshwater fish. Progress in Lipid Research, v. 26, p. 281-347, 1987.

[11] KEYS, A.; ANDERSON, J. T.; GRANDE, F. Serum cholesterol response to changes in the diet. IV. Particular saturated fatty acids in the diet. Metabolism, v. 14, n.4, p. 776-779, 1965.

[12] KHOSLA, P.; SUNDRAM, K. Effects of dietary fatty acid composition on plasma cholesterol. Progress Lipid Research, v. 35, n.1, p. 93-132, 1996.

[13] KIMURA, Y.; TAKAKU, T.; NAKAJIMA, S.; OKUDA, H. Effects of carp and tuna oils on 5-fluorouracil-induced antitumor activity and side effects in sarcoma 180-bearing mice. Lipids, v. 36, p. 353-59, 2001.

[14] KINSELLA, J. E.; SHIMP, J. L.; MAI, J.; WEIHRAUCH, J. Fatty acid content and composition of freshwater finfish. Journal of the American Oil Chemical Society, v. 54, 424-429, 1977.

[15] KROMANN, N.; GREEN, A. Epidemiological studies in the Upernavik district, Greenland. Acta Medica Scandinavica, v. 208, p. 401-06, 1980.
[16] LUZIA, L. A.; SAMPAIO, G. R.; CASTELLUCCI, C. M. N.; TORRES, E. A. F. S. The influence of season on the lipid profiles of five commercially important species of Brazilian fish. Food Chemistry, v. 83, p. 93-97, 2003.

[17] MAIA, E. L.; RODRIGUEZ-AMAYA, D.B.; FRANCO, M. R. B. Fatty acids of the total, neutral, and phospholipids of the Brazilian freshwater fish Prochilodus scrofa. Journal of Food Composition and Analysis, v. 7, p. 240-251, 1995.

[18] MOREIRA, A. B.; VISENTAINER, J. V.; SOUZA, N. E.; MATSUSHITA, M. Fatty acids profile and cholesterol contents of three Brazilian brycon freshwater fishes. Journal of Food Composition and Analysis, v.14, p. 565-74, 2001.

[19] NOGUEIRA, G.C.; BRAGAGNOLO, N. Anais XVIII Congessso Brasileiro Ciência e Tecnologia Alimentos, v. 1, p. 328-332, 2002. CD-Rom.

[20] OGAWA, M.; KOIKE, J. Manual de pesca. Associação dos Engenheiros de Pesca do Estado do Ceará, Fortaleza/CE. 1987.797p.

[21] PUWASTIEN, P.; JUDPRASONG, K.; KCTTWAN, E.; VASANACHITT, K.; NAKNGAMANONG, Y.; BHATTACHARJCC, L. Proximate composition of raw and cooked Thai freshwater and marine fish. Journal of Food Composition and Analysis, v. 12, p. 9-16, 1999.

[22] ROSE, D. P.; CONNOLLY, J. M. Omega-3 fatty acids as cancer chemopreventive agents. Pharmacology and Therapeutics, v. 83, p. 217-44, 1999.

[23] STATISTICA, (1995). Statistica 5.0 Software. Stasoft, Tucksa.

[24] VISENTAINER, J.V. Composição de ácidos graxos e quantificação dos ácidos graxos LNA, EPA e DHA no tecido muscular de tilápias (Oreochromis niloticus), submetidas a diferentes tratamentos com óleo de linhaça. Campinas. 2003. (Tese de doutoradoUniversidade Estadual de Campinas).

[25] VISENTAINER, J.V.; MATSUSHITA, M.; SOUZA, N. E.; CATHARINO, R. R.; FRANCO, M. R. B. Composição quimica e de ácidos graxos em tilápias (Oreochromis niloticus) submetidas à dieta prolongada. Revista Nacional da Carne, v. 3, 109-112, 2003.

[26] Zenebe, T.; AhlgREN, G.; Gustafsson, I. B. Fatty acid and lipid content or Oreochromis niloticus L. in Ethiopian lakes - dietary effects of phytoplankton. Ecology of Freshwater Fish. Journal of Fish Biology, v. 7 , p. 146-58, 1998. 